\section{Stigma related to bipolar disorder in the perception of psychiatrists from Belo Horizonte, Minas Gerais State, Brazil}

\author{
Estigma relacionado ao transtorno bipolar de \\ acordo com psiquiatras em Belo Horizonte, \\ Estado de Minas Gerais, Brasil
}

\section{Estigma relacionado con el trastorno bipolar según psiquiatras en Belo Horizonte, Estado de Minas Gerais, Brasil}

\begin{abstract}
This research sought to understand meanings and implications of the stigma related to bipolar disorder in relation to social processes and local cultural value systems. Seven semidirected individual interviews were performed with psychiatrists (from Belo Horizonte city, Minas Gerais State, Brazil) and analyzed with referential from the Medical Anthropology. Some potential stigmatizing views about bipolar disorder patients were endorsed by respondents related to biomedical model of bipolar disorder. They claimed about the extreme trivialization of this diagnosis nowadays and observed that, in spite of the mitigation of stigma related to bipolar disorder over time, it remains an important issue, especially at labor fields and as a cause of refusal of treatment.
\end{abstract}

Bipolar Disorder; Social Stigma; Medical Anthropology

\author{
Adauto Silva Clemente 1 \\ Wagner Jorge dos Santos 1 \\ Rodrigo Nicolato 2 \\ Josélia Oliveira Araújo Firmo 1
}

doi: 10.1590/0102-311X00050016

\author{
Correspondence \\ A. S. Clemente \\ Centro de Pesquisas René Rachou, Fundação Oswaldo Cruz. \\ Av. Augusto de Lima 1715, sala 611, Belo Horizonte, MG \\ 30190-002, Brasil. \\ adautoclemente@yahoo.com.br \\ 1 Centro de Pesquisas René Rachou, Fundação Oswaldo Cruz, \\ Belo Horizonte, Brasil. \\ 2 Faculdade de Medicina, Universidade Federal de Minas \\ Gerais, Belo Horizonte, Brasil.
}




\section{Introduction}

Bipolar disorder is, potentially, one of the most serious mental disorders, with high social and personal costs 1,2 and increased risk of suicide ${ }^{3}$. It is characterized by the variable switching between recurring depressive and manic/hypomanic episodes. Its lifetime prevalence is $1-2 \%$, and may reach more than 5\% using less conservative criteria to the diagnosis 4 . Despite the existence of effective treatments, the adherence is usually low 5 .

Stigma towards people with mental disorders has been recognized as an important barrier to help-seeking and using mental health services 6,7 , resulting in a vicious circle between marginalization and illness 8 . Stigma was defined as negative appreciation of an individual based on some derogatory attributes from which other negative characteristics are inferred 9 . According to this conception, the presence of a mental disorder modifies the perception and the public attitudes in relation to some individuals, activating a number of stereotypes and responses that will influence the person's interaction network 10 .

Stigma and mental health have been studied by the following main disciplinary perspectives. The first focuses on psychological and social processes and it highlights processes of labeling, discriminatory interpersonal relationships, and personal experience of stigmatized individuals or groups. Another conception considers structural conditions, such as the existing power relationships, macrosocial, cultural, institutional forces, and policies, which reduce opportunities or limit the rights of disadvantaged individuals 11 . Such structural discrimination can be observed even in health systems, where the availability and quality of mental health services are generally worse than other medical services 12,13 . From a cultural perspective, stigma is experienced in a peculiar way in each local reality, shaped by different cultural contexts, social structures, and particular cultural values 14 . These values influence its expression and perpetuation as a moral experience set around the most fundamental values in a group's everyday social life 15,16,17.

Studies on mental illness and stigma have focused mainly on depression, schizophrenia and other psychotic disorders or mental disorders in general. The few existing researches have showed that people with bipolar disorder are also stigmatized in different sectors of their lives 18,19,20.

In this study, we intended to explore stigma related to bipolar disorder as perceived by psychiatrists. These professionals represent an essential link on this play of forces related to the mental disorders: they are directly involved in assistance and their attitudes have influence on the public opinion and on the approach of individuals with mental disorders. We sought to understand meanings and implications of the stigma regarding social processes, power relationships and local cultural value systems.

\section{Methodological approach}

We used the ethnographic model and the theoretical framework of Medical Anthropology with interpretative approach, under the perspective of Kleinman \& Benson 21, whereby culture includes the processes by which activities and common conditions take emotional tones and moral senses for the individuals.

The research was conducted in the city of Belo Horizonte, the capital of the state of Minas Gerais, Brazil, whose metropolitan area has more than 5 million inhabitants and concentrates emigrations and services for the population of a much larger geographical area. The city has a mental healthcare network consisting of outpatient and hospital services, in public and private systems and through health insurance. In private clinics, psychiatrists exert their activity with greater autonomy and receive customers with greater purchasing power compared with the public service. Commonly, these professionals began their professional life in the public service and maintained in parallel their own private offices, where there is greater possibility of financial gain, which is fully engagedafter retirement.

Participants were selected from a list indicated by a key informant, who chaired the local psychiatric association. This list contained names of psychiatrists in activity who had started their clinic practice before 1980, which is useful to address the changes in the paradigms of psychiatric practice 
and the conceptual changes on bipolar disorder since its introduction in contemporary psychiatric diagnostic manuals. From that list, we seek to select the participants to include the greatest possible diversity in terms of gender, type and local of their professional activities as psychiatrists.

Until the 1980s, local psychiatric care and psychiatric training took place in a predominantly hospital-centric model of care. The theoretical references that supported the psychiatry practiced at that time were mainly psychoanalysis and phenomenological psychopathology. In the 1970s the Psychiatric Reform movement began, which questioned and influenced subsequent changes in health policies and psychiatric care. At that time there was also a paradigm shift in psychiatric classification brought by the 3rd edition of the Diagnostic and Statistical Manual of Mental Disorders (DSM-III), published in 1980, which established goals and new concepts of diagnostic criteria. In the Brazilian context, such change has greater influence on psychiatric practice since the 1990s with the publication of the 10th revision of the International Classification of Diseases (ICD-10).

The collection and analysis of data were based on the model of Signs, Meanings and Actions aiming to clarify underlying cultural logics about the group's practices, their meanings and signs related to them 22. Participation was voluntary, obtained after reading and signing an Informed Consent Form. We ensure the anonymity of the participants by using codes for each one. The research was approved by the Ethics Research Committee of the René Rachou Research Center, Oswaldo Cruz Foundation (CAAE 15108113.9.0000.5091), in accordance with the resolution of Brazilian National Health Council on research involving humans (CNS 466/2012).

Single semi-structured interviews were conducted between October 2012 and June 2013. We used triggering questions to evoke perceptions of the stigma related to bipolar disorder and its relation to the conceptual changes about this disorder over the years. Interviews were recorded and transcribed by the researchers themselves, immediately after each interview. The number of participants was defined according to saturation criteria 23: the inclusion of new participants was suspended when the data obtained became repetitive and considered sufficient to clarify the logic that based group practices in relation to the subject studied. Each interview was repeatedly read to identify explicitly or implicitly communicated actions. Such actions were organized in analytical categories, selected according to their emphasis and importance as other contents of the interviews, interpreted to clarify the underlying cultural logic to group practices, their meanings and signs related to them. We used the Contextual Semantic Interpretation to contextualize findings with broader meaning systems that allowed us to explore the interaction between cultural processes and structural forces in the production and maintenance of the stigma, in dialogue with the available literature on these topics 24 .

\section{Results}

Seven psychiatrists were interviewed, four of them were male. With one exception, all of them work or worked in the public psychiatric service. Only one has never worked in a psychiatric hospital, and all are currently working in their own private offices.

Participants asserted with great concordance that there was a significant mitigation of stigma related to bipolar disorder over time. According to them, nowadays, patients accept more easily the diagnosis and even admit it publicly in some situations. They highlighted the positive impact of change in psychiatric classification due to the lower stigmatization of the diagnostic of bipolar disorder in relation to previous manic-depressive psychosis category.

"I think that there isn't much of this stigma. I think that the manic-depressive psychosis has a bigger stigmatization power, while the bipolarity doesn't' (Respondent 3).

Distrusts in relation to the patient with bipolar disorder are most observed in the labor area, with uncertainties about their capacities and restrictions on access to opportunities. Due to this, they notice the tendency to hide the diagnosis in work situations and they often have to intervene to prevent professional losses to their patients. In other fields of life, such as civil rights and interpersonal relationships, stigma is supposed but not noticed by respondents.

"They want to go back to work but there are no opportunities" (Respondent 5).

In contrast to the strong stigma associated with manic-depressive psychosis in the past, recently, psychiatrists have noticed an extreme trivialization of the bipolar disorder diagnosis, applied 
indiscriminately to characterize any humor variation, and the growing phenomenon of self-diagnosis, in which the patient seeks the professional only to confirm the bipolar disorder diagnosis.

"On one hand, this approach of the diagnosis with normality was positive; on the other hand, it has been moving towards trivialization" (Respondent 2).

"I've received patients in my office that said: 'I am bipolar', as if it was not a serious illness... This undoes the idea that it is a psychosis. I say that I have patients who are really bipolar and some patients that are pseudobipolar" (Respondent 7).

Participants consider that stigma is a reality for all severe mental disorders, including some cases of bipolar disorder. They think that this extends to their families and to psychiatrists.

Some terms were used by respondents to characterize the nature of the bipolar disorder: disease, illness, weakness or problem. They alternately refer to that with the expressions being a bipolar patient or having bipolar disorder or just bipolarity.

The patients were described as unpredictable, uncontrollable, and potentially dangerous to themselves and especially to their family and their own possessions. The chronic nature was an aspect fairly attributed to the bipolar disorder. Aggressive behavior was not directly related to bipolar disorder, but was invoked when talking about mental disorders in general, or some comorbid conditions, such as substance use.

"This sensation of not knowing who they are, of falling asleep in a way and waking up in a different way (...). I had a patient who caused problems on a trip, a huge expense" (Respondent 2).

"The patients have to understand that they have a chronic condition, and therefore, their care will also have to be chronic" (Respondent 4).

Schizophrenia was repeatedly evoked as a comparison because it carries significant stigma, greater than bipolar disorder, which is seen as less disabling from the point of view of social relationships and functional capabilities.

"In the bipolar disorder condition, the patient's life can be very good. We usually read about a higher incidence of self-extermination, a cognitive loss... I don't see that seriously happening" (Respondent 1).

Respondents claim that stigma related to bipolar disorder must be fought. The information based on scientific knowledge (sometimes referred to as education or psychoeducation) was the main intervention mentioned to combat the stigma related to bipolar disorder.

"The more information the person has, the better for that person" (Respondent 4).

They also defended the humanization of psychiatrist practice, by considering the personal experience of each patient and promoting their participation and responsibility in their treatment. "I try to have the patient as an ally so we have a shared decision" (Respondent 3).

"So, what is a patient? A human being. He [doctor] seeks in humans the healthy part of it, not the unhealthy part. The whole person" (Respondent 6).

They believe that treatment minimizes the stigma by reducing the symptoms. Furthermore, they suggested that treatment should target stability. The therapeutic approach was often compared with other chronic medical conditions, argument that is even used by professionals in an attempt to convince their patients about the importance of treatment.

"You have to treat depression, mania, and treat the person in the inter-critical period. Usually the result is positive, almost all of them stabilize and have a normal life" (Respondent 7).

"If you have hypertension and do not take care of it, you will have a health problem. Everything in life is like that; we have to take care of ourselves" (Respondent 1).

Stigma was explicitly mentioned as a cause of refusal to diagnosis or to treatment for mental disorders, but this is not often observed in depressive and inter-episodic phases of bipolar disorder. In manic, as well as in severe depressive episodes, the patient does not usually have morbidity awareness (or insight), in other words, the person does not recognize the change in his mental state, being likely to refuse treatment. Mania seems to be less tolerated by people, which leads to the initiative of family members or others to take the patient for treatment.

"It is the fact of losing, with these conditions, the ability of having a correct self-awareness" (Respondent 4).

Once started, other reasons may lead to discontinuation of treatment, such as the presence of adverse effects of drugs and the fact of feel well during the inter-episodic phase.

"As they feel good, they think that they will no longer need medicine. And the tendency is to forget about it" (Respondent 5). 


\section{Discussion}

There was agreement on the attenuation of stigma over the past decades with the change of nomenclature for bipolar disorder. Respondents ascribe this to mischaracterization of these conditions as psychosis. This reduction of stigma can be attributed to a greater acceptance of bipolar disorder diagnosis and the increasing trend to self-diagnosis of bipolar disorder in recent years 25 .

Despite its potential benefits, this phenomenon also imply risks and disadvantages, especially the trivialization of bipolar disorder diagnosis. The trivialization is related to excessive use of psychiatric labels and the intense penetration of psychiatry and its logic to understand life experiences. Patients often seek a psychiatric diagnosis as a way to understand the phenomena they suffer and find out solutions. The trivialization of bipolar disorder diagnosis implies a duality because, on one hand, it helps to reduce the stigma related to this disorder, on the other hand, it can lead to overdiagnosis of bipolar disorder, both by professionals and by many individuals who identify themselves with this disorder and begin to seek and require medical interventions 25,26 .

Maybe, under bipolar disorder diagnosis, patients attempt to avoid adjectives with intense moral judgment (wasteful, irresponsible, lazy, uncontrolled) or other more stigmatized mental disorders (such as schizophrenia, some personality disorders, or dissociative disorders). Cultural influences frame the presentation of a mental discomfort in a more suitable way of expression according to those cultural values 27 . Some characteristics attributed to bipolar disorder seem appropriate to the post-modern capitalist experiences and values, such as experiences of instability or the appreciation of individuals by their autonomy, productivity, and consumer potential 28.

In accordance with the findings and the literature, respondents asserted that labor is the field of experience in which discrimination of bipolar disorder patients is more substantial. For them, it often involves dilemmas about disclosure of diagnosis 29 . In the most economically developed societies, individuals who do not fit in the dynamics of work show greater commitment to their wider social relations, while in developing societies, there is usually greater tolerance and cohesion that favors the social acceptance of these individuals 30 . In the Brazilian society, the concurrent presence of both development conditions could explain the greater acceptance of bipolar disorder patients in social and familiar settings, where traditional values are more preserved than in labor relations, which are more influenced by the globalized and capitalist cultures.

In controversial or morally charged issues, such as stigma, ambivalence is usually not easily communicated or individuals can abstract or suppress negative feelings 31 . Nevertheless, we noted the duality between the concern of respondents to transmit a humanized attitude and free of prejudices, while stereotypes related to bipolar disorder were raised spontaneously and quite naturally (such as instability, unpredictability, and chronicity), the same features were present in the descriptions of this disorder in professional guides.

Respondents have also ratified the psychopathological conception about the impairment of insight - a term that refers to the patient's ability to associate their symptoms with the presence of a disease that requires medical treatment 32 - that prevails in biomedical conception as a manifestation of the disorder itself, especially during manic symptoms. However, the consequences of the lack of insight can vary in different clinical situations and, in addition to its pathological and psychological bases, can also be understood as social and cultural processes, with influences, for example, from the perceived stigma and the ability to identify with a social group 33 . From this perspective, one must understand that the medical language, rather than a simple mirror of the empirical world, constitutes a rich cultural language that plays a version of reality with highly specialized moral conceptions and founded on the system of social relations with which it shares meanings and values with their technical functions 34 .

Although sensible to structural factors that perpetuate stigma, when proposing interventions to address it, they are restricted to the psychological and interpersonal aspects, highlighting the task of informing the patient about the disorder and its consequences. The emphasis to fight the stigma implicitly borne mainly in the stabilization achieved by pharmacological resources. Regarding compliance to treatment, we observed that the concern about the resistance of the individual predominates over the other factors that are known to interfere on the access to and during treatment, disregarding the structural barriers present in the difficulties of access. This attitude is in tune with the biomedical tradition, which tends to focus on individual interventions and undervalue the social 
aspects involved in determining health problems. We stress that the professional group studied, by its predominant current acting in their private practices, possibly deals with a population with less serious disorders and with greater resources of life and access to treatment.

Psychiatrists may be seen as components of a social control network, since it is up to them to recognize individuals who exceed certain limitations, provide them with a diagnosis and suggest interventions to restore the disturbed order 35 . The idea of control was often referred by our respondents as necessary to achieve good outcomes for patients, either by controlling the symptoms or even with restrictive actions, such as the involuntary psychiatric hospitalization. Such interventions are included as anti-stigma measures, because they favor the control of symptoms. Literature partially supports this view, but points out that psychiatric hospitalization is associated with stigma and negative effects on self-esteem and quality of life 36 , an aspect little regarded by them.

Some psychiatrist's practices may contribute to the perpetuation of stigmatizing attitudes, and their professional struggle itself, in defense of their patients, can reinforce certain stereotypes of people with mental disorders 37,38 . They believe, for example, that the application of the medical model to bipolar disorder by comparing it with other diseases of chronic evolution can reduce stigma and improve the adherence. This perspective, however, has demonstrated limitations and even opposite results. The message that "mental disorders are diseases like others" helps to reduce stigmas of weaknesses of character or guilt of the individual and promotes the search for treatment 35,39, but intensifies some pernicious stereotypes, such as incurability, incapacity, unpredictability, and dangerousness 40,41,42.

Education was referred to as way of fighting stigma through information about the disorder and by promoting the acceptance and adherence to treatment. These views find support in the literature, which shows good results of cognitive and educational interventions gathered in therapeutic programs, such as groups of psychoeducation. However, stigmatizing attitudes are not necessarily related to lack of knowledge, but also with the kind of information transmitted 43.

Addressing stigma implies that health professionals are willing to promote the therapeutic relationship by considering the expectations of patients and their participation in decisions, which reduces the self-deprecation and a sense of disbelief, and tends to improve adherence to treatment and quality of life 29 . Our respondents proved to be sensitive to this aspect of the clinic, although without declaring it explicitly as a stigma coping action.

\section{Limitations}

We consider the susceptibility of interviews to socially desirable answers, particularly because negative conceptions of mental disorders may constitute a taboo for the group studied.

This research aimed to understand the stigma of bipolar disorder only within the limits of perception of psychiatrists. We believe, however, that the results allowed relevant understanding concerning some aspects related to stigma experienced by persons with bipolar disorder, as perceived by psychiatrists.

\section{Conclusion}

By exploring in an unprecedented way the psychiatrists' perspective, this study may have broaden the understanding of stigma related to bipolar disorder and their implications and about the forces and conditions that contribute to its maintenance. Thus, their findings may guide future research on the subject and create public policies or interventions to combat this stigma at different levels.

At the structural level, one of the most important measures to combat the stigma of people with mental disorders regards their own interactions with professionals and health services. In this study, cultural attitudes and practices that reproduce a particular moral domain were identified, which may inadvertently contribute to reinforce stereotypes and discrimination, even in their own efforts to fight stigma.

The study of the stigma associated with bipolar disorder can make relevant contributions in understanding the phenomenon of mental disorders in general, since this diagnosis includes, under 
the same label, manifestations of varying severity, from severe and incapacitating episodes, which may include psychotic symptoms, to slight manifestations and lower morbidity. We hope it provides tools to better approach and management of the stigma issue with bipolar disorder and other mental disorders by health professionals.

\section{Contributors}

A. S. Clemente participated in the study design, transcription of the interviews, development and analysis of the data, and writing of the article. W. J. Santos and J. O. A. Firmo contributed in the study design, interviews, development and analysis of the data, writing of the article, and review. R. Nicolato participated in the study design, development and analysis of the data, and writing of the article.

\section{Acknowledgments}

This article was supported in part by grants from Brazilian Graduate Studies Coordinating Board (Capes), Brazilian National Research Council (CNPq; productivity scholarship 302614/20117) and Minas Gerais State Research Foundation (Fapemig; CDS-APQ-00512-1). 


\section{References}

1. Crump C, Sundquist K, Winkleby MA, Sundquist J. Comorbidities and mortality in bipolar disorder: a Swedish national cohort study. JAMA Psychiatry 2013; 70:931-9.

2. Fagiolini A, Forgione R, Maccari M, Cuomo A, Morana B, Dell'Osso MC, et al. Prevalence, chronicity, burden and borders of bipolar disorder. J Affect Disord 2013; 148:161-9.

3. Pompili M, Gonda X, Serafini G, Innamorati M, Sher L, Amore M, et al. Epidemiology of suicide in bipolar disorders: a systematic review of the literature. Bipolar Disord 2013; 15:457-90.

4. Akiskal HS, Bourgeois ML, Angst J, Post R, Möller H, Hirschfeld R. Re-evaluating the prevalence of and diagnostic composition within the broad clinical spectrum of bipolar disorders. J Affect Disord 2000; 59 Suppl 1:S5-30.

5. Leclerc E, Mansur RB, Brietzke E. Determinants of adherence to treatment in bipolar disorder: a comprehensive review. J Affect Disord 2013; 149:247-52.

6. Clement S, Schauman O, Graham T, Maggioni F, Evans-Lacko S, Bezborodovs N, et al. What is the impact of mental health-related on helpseeking? A systematic review of quantitative and qualitative studies. Psychol Med 2015; 45:11-27.

7. Corrigan P. How stigma interferes with mental health care. Am Psychol 2004; 59:614-25.

8. Stuber J, Meyer I. Stigma, prejudice, discrimination and health. Soc Sci Med 2008; 67:351-7.

9. Goffman E. Stigma: notes on the management of spoiled identity. New York: Touchstone; 1986.

10. Link BG, Cullen FT, Frank J, Wozniak JF. The social rejection of former mental patients: understanding why labels matter. Am J Sociol 1987; 92:1461-500.

11. Link BG, Phelan JC. Stigma and its public health implications. Lancet 2006; 367:528-9.

12. Saxena S, Thornicroft G, Knapp M, Whiteford H. Resources for mental health: scarcity, inequity, and inefficiency. Lancet 2007; 370:878-89.
13. Tsao CIP, Tummala A, Roberts LW. Stigma in mental health care. Acad Psychiatry 2008; 32:70-2.

14. Murthy RS. Stigma is universal but experiences are local. World Psychiatry 2002; 1:28.

15. Kleinman A, Wang WZ, Li SC, Cheng XM, Daí XY, Li KT, et al. The social course of epilepsy: chronic illness as social experience in interior China. Soc Sci Med 1995; 40:1319-30.

16. Kleinman A, Hall-Clifford R. Stigma: a social, cultural and moral process. J Epidemiol Community Health 2009; 63:418-9.

17. Yang LH, Chen F-P, Sia KJ, Lam J, Lam K, Ngo $\mathrm{H}$, et al. "What matters most": a cultural mechanism moderating structural vulnerability and moral experience of mental illness stigma. Soc Sci Med 2014; 103:84-93.

18. Bilderbeck AC, Saunders KE, Price J Goodwin GM. Psychiatric assessment of mood instability: qualitative study of patient experience. $\mathrm{Br} J$ Psychiatry 2014; 204:234-9.

19. Ellison N, Mason O, Scior K. Bipolar disorder and stigma: a systematic review of the literature. J Affect Disord 2013; 151:805-20.

20. Hawke LD, Parikh SV, Michalak EE. Stigma and bipolar disorder: a review of the literature. J Affect Disord 2013; 150:181-91.

21. Kleinman A, Benson P. Anthropology in the clinic: the problem of cultural competency and how to fix it. PLoS Med 2006; 3:e294.

22. Corin E, Uchoa E, Bibeau G, Kourmare B. Articulation et variations de systèmes de Signes, de Sens et d'Action. Psychopatologie Africaine 1992; XXIV:2183-204.

23. Fontanella BJB, Ricas J, Turato ER. Amostragem por saturação em pesquisas qualitativas em saúde: contribuições teóricas. Cad Saúde Pública 2008; 24:17-27.

24. Bibeau G, Corin EE. From submission to the text to interpretative violence. In: Bibeau G, Corin EE, editors. Beyond textuality: asceticism and violence in anthropological interpretation. Berlin: Mounton de Gruyter; 1994. p. 1-54. 
25. Chan D, Sireling L. 'I want to be bipolar'.. a new phenomenon. Psychiatrist 2010; 34:103-6.

26. Montanini D, Banzato CEM. Do estigma da psicose maníaco-depressiva ao incentivo ao tratamento do transtorno bipolar: a evolução da abordagem em dois veículos midiáticos nos últimos 40 anos. J Bras Psiquiatr 2012; 61:84-8.

27. Lin EHB, Carter WB, Kleinman AM. An exploration of somatization among Asian refugees and immigrants in primary care. Am J Public Health 1985; 75:1080-5.

28. Martin E. Bipolar expeditions: mania and depression in American culture. Princeton: Princeton University Press; 2007.

29. Michalak EE, Yatham LN, Kolesar S, Lam RW. Bipolar disorder and quality of life: a patientcentered perspective. Qual Life Res 2006; 15:25-37.

30. Littlewood R. Cultural variation in the stigmatization of mental illness. Lancet 1998; 352:1056-7.

31. Crocker J, Major B. Social stigma and selfsteem: the self-protective properties of stigma. Psychol Rev 1989; 96:608-30.

32. David AS. Insight and psychosis. Br J Psychiatry 1990; 156:798-808.

33. Mishra DK, Alreja S, Sengar KS, Singh AR. Insight and its relationship with stigma in psychiatric patients. Ind Psychiatry J 2009; 18:39-42.

34. Good BJ. Medicine, rationality, and experience: An anthropological perspective. Cambridge: Cambridge University Press; 1994.

35. Wahl O. Mental health consumers' experience of stigma. Schizophr Bull 1999; 25:467-78.
36. Link BG, Castille D, Stuber J. Stigma and coercion in the context of outpatient treatment for people with mental illnesses. Soc Sci Med 2008; 67:409-19.

37. Lauber C, Nordt C, Braunschweig C, Rössler W. Do mental health professionals stigmatize their patients? Acta Psychiatr Scand Suppl 2006; (429):51-9.

38. Sartorius N. Iatrogenic stigma of mental illness. BMJ 2002; 324:1470-1.

39. Pattyn E, Verhaeghe M, Sercu C. Medicalizing versus pscyhologizing mental illness: what are the implications for help seeking and stigma? A general population study. Soc Psychiatry Psychiatr Epidemiol 2013; 48:1637-45.

40. Angermeyer MC, Beck M, Matschinger H. Determinants of the public's preference for social distance from people with schizophrenia. Can J Psychiatry 2003; 48:663-8.

41. Lincoln TM, Arens E, Berger C, Rief W. Can antistigma campaigns be improved? A test of the impact of biogenetic versus psychosocial causal explanations on implicit and explicit attitudes to schizophrenia. Schizophr Bull 2008; 34:984-94.

42. Read J, Haslam N, Sayce L, Davies E. Prejudice and schizophrenia: a review of the "mental illness is an illness like any other" approach. Acta Psychiatr Scand 2006; 114:303-18.

43. Nordt C, Rössler W, Lauber C. Attitudes of mental health professionals toward people with schizophrenia and major depression. Schizophr Bull 2006; 32:709-14. 


\section{Resumo}

O estudo teve como objetivo compreender os significados e implicações do estigma relacionado ao transtorno bipolar em relação aos processos sociais e sistemas de valores culturais locais. Foram realizadas sete entrevistas individuais semiestruturadas com psiquiatras em Belo Horizonte, Estado de Minas Gerais, Brasil, analisadas com o referencial da Antropologia Médica. Algumas visões potencialmente produtoras de estigma em relação a pacientes com transtorno bipolar foram endossadas pelos entrevistados, relacionadas ao modelo biomédico do transtorno bipolar. Os entrevistados alegavam uma extrema banalização do diagnóstico, observando que, apesar da mitigação do estigma relacionado ao transtorno bipolar com o passar do tempo, ainda é uma questão importante, principalmente no campo do trabalho e como causa de recusa de tratamento.

Transtorno Bipolar; Estigma Social;

Antropologia Médica

\section{Resumen}

El objetivo de este estudio fue comprender los significados e implicaciones del estigma relacionado con el trastorno bipolar, en relación con los procesos sociales y sistemas de valores culturales locales. Se realizaron siete entrevistas individuales semiestructuradas con psiquiatras en Belo Horizonte, Estado de Minas Gerais, Brasil, analizadas con el referencial de la Antropología Médica. Algunas visiones potencialmente productoras de estigma, en relación a pacientes con trastorno bipolar fueron transmitidas por los entrevistados, relacionadas con el modelo biomédico del trastorno bipolar. Los entrevistados alegaban una extrema banalización del diagnóstico, observando que, a pesar de la mitigación del estigma relacionado al trastorno bipolar con el paso del tiempo, todavía es una cuestión importante, principalmente en el campo de trabajo $y$ como causa de rechazo del tratamiento.

Trastorno Bipolar; Estigma Social; Antropología Médica
Submitted on 27/Mar/2016

Final version resubmitted on $01 / \mathrm{Jul} / 2016$

Approved on 24/Ago/2016 